\title{
Resonant-Type loop antenna loaded with CRLH Unit cell
}

\author{
N.R.Indira ${ }^{1}$, A. Ameena Banu², A. Aruna Anbarasi ${ }^{3}$ \\ Associate Professor, ECE, Sethu Institute of Technology, Virudhunagar, India ${ }^{1,2}$ \\ Assistant professor, Sethu Institute of Technology, Virudhunagar, India ${ }^{3}$
}

\begin{abstract}
The concept of loading monopole antennas with composite right/left-handed (CRLH) unit cell is extended to cover other types of resonant antennas, namely loop antennas. The proposed structure consists of a Loop antenna loaded with a composite right/left-handed (CRLH) unit cell, operates at two narrow band $0.9 \mathrm{GHz}, 1.57 \mathrm{GHz}$ and one wide band around $2.6 \mathrm{GHz}$. It covers several communication standards. By adding one unit cell, these antennas achieve three operating bands while their sizes unmodified. The new frequencies are lower than the unloaded antenna's nominal frequency.
\end{abstract}

Keywords: Composite right/left handed (CRLH) structure, Meta material, Loop antenna

\section{INTRODUCTION}

The demand for wireless systems are designing broad band \& multiband antennas [2].The recently invented metamaterial-based antennas demonstrate not only wide operating bandwidth, high antenna efficiency, high gain, but also significantly reduced volume with simple mechanical structures[3]. Specifically, they demonstrated high potential in designing electrically small antennas [4], [5] and multiband operating antennas [6], [7].Recently [8], the authors have demonstrated the concept of loading conventional microstrip-fed monopole antenna with a composite right/left-handed (CRLH) unit cell, which has led to triple-band operation, while maintaining a monopole-like radiation pattern at all operating bands. The three operating bands were verified to correspond to the unit cell's stop, left-handed, and right-handed bands, respectively. The concept was generalized in [1] by loading the monopole with more than one CRLH unit cell, leading to more operating bands. In this paper, we show that using CRLH unit cells to enhance the antenna performance is not pertinent to monopole antennas only, but can be applied to other resonant-type antennas as well.

\section{FUNDAMENTALS OF CRLH METAMATERIALS}

The equivalent circuit and three implementations (onedimensional, two-dimensional, and three-dimensional) of periodic CRLH metamaterials are shown Figure1. It should be noted that periodicity is here a convenience but not a necessity, as long as the largest cell is much smaller than the guided wavelength ( $\mathbf{p}<<\mathbf{A g}$ ) for electromagnetic homogeneity. Another important note is that as long as the effective-medium condition, $\mathbf{p}<\mathbf{A g}$, is satisfied, there is no constraint on the minimum number of unit cells required for metamaterial operation. Even one single cell, when perfectly matched to the external world (i.e., presenting a Bloch impedance equal to that of the external media or ports), behaves in a manner that cannot be distinguished from the behavior of a perfectly continuous medium of the same electrical size for the wave crossing it.

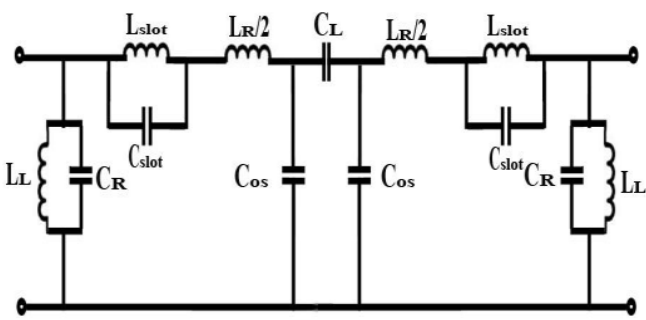

Fig 1. A Equivalent circuit of CRLH transmissionline unit cell

\section{III.Crlh Unit-Cell Design}

The conventional CRLH unit cell presented in Fig. 2(a). It relies on the inter digital capacitor to provide the series capacitance and on the shunt short-circuited stub to provide the parallel inductance. Three modifications on this unit cell are made to lead to the unit cell shown in Fig. 2(b). First the unit cell is made symmetric so that even if the unit cell radiates, the radiation from the right side will cancel the radiation from the left side and the radiation pattern will be controlled mainly by the monopole. Second, the capacitor is rotated to reduce its length in the lateral direction so that the unit cell occupies a small portion of the monopole. Finally, additional short-circuited stubs are added before the inter digital capacitor to enhance the inductance of the unit cell. The upper and lower stubs are connected by one via to the ground to reduce the number of vias required. It should be noted that the ground of the CRLH unit cell is not connected to the main ground of the loop antenna. Dispersion relation calculated for the balanced with CRLH Unit cell is shown in Fig 3

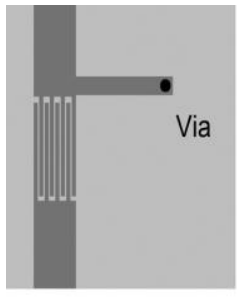

(a)

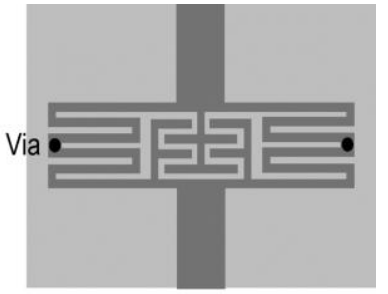

(b)
Fig. 2. (a) CRLH unit cell presented (b) Modified CRLH unit 


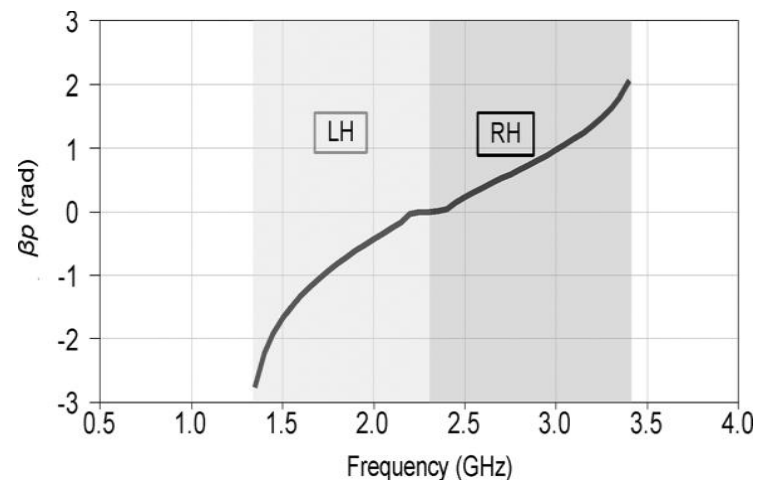

Fig. 3. Dispersion relation calculated for the balanced CRLH unit cell with dimensions

\section{IV .LOOPANTENNA LOADED WITH CRLH UNIT}

First, the concept is applied to the loop antenna, Fig. 4(a), shows the loop antenna with CRLH Unit cell.

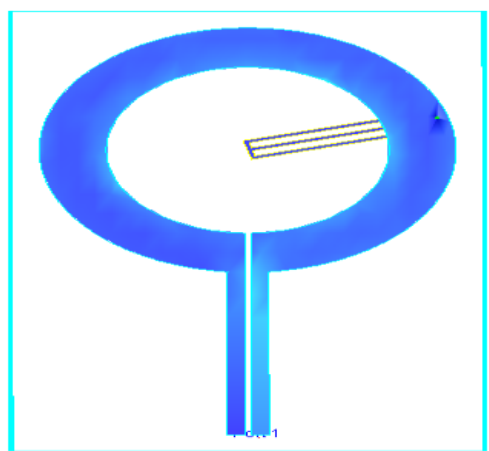

Fig 4.Loop antenna loaded with CRLH

The CRLH unit cell is designed such that the loaded antennas occupy exactly the same size as the unloaded ones so that multiband operation can be obtained.

In the proposed system, the loop antenna with metamaterial will be used to improve the performance of the antenna.[11-12] Here CRLH metamaterial is used to improve the performance of the loop antenna. In this case, CRLH unit cell is designed such that the loaded antennas occupy exactly the same size as the unloaded ones, and also multiband operation can be achieved.

The proposed loop antenna is shown in Fig.4 One of the main reasons that the unit cell in was made symmetric is that the radiation of the right half cancels that of the left half, and the radiation pattern is controlled mainly by the loop antenna. This came at the expense of large size in the lateral direction.

In this case, only one half of the unit cell is used in order to best utilize the area inside the loop at the expense of altering the radiation pattern. The design starts by loading the antenna with a lumped-component CRLH unit cell that has the form of a pi-network. Shown table 1
TABLE I

Dimensions Of The Antenna Presented In The Letter (In Millimeters)

\begin{tabular}{|l|l|}
\hline SYMBOL & LOOP ANTENNA \\
\hline Lg & 95 \\
\hline Wg & 65 \\
\hline L1 & 31 \\
\hline L2 & - \\
\hline L3 & - \\
\hline L4 & - \\
\hline L5 & - \\
\hline L6 & - \\
\hline L7 & - \\
\hline L8 & - \\
\hline S1 & 0.7 \\
\hline Radius & 19 \\
\hline O & $75^{\circ}$ \\
\hline W1 & 2 \\
\hline W2 & 9 \\
\hline W3 & 0.5 \\
\hline W4 & 1 \\
\hline W5 & 1.5 \\
\hline W6 & - \\
\hline W7 & - \\
\hline Lc & 17.5 \\
\hline Wc & 0.55 \\
\hline Sc & 0.3 \\
\hline Ls & 3.15 \\
\hline Ws & 0.47 \\
\hline Ss & 0.3 \\
\hline & \\
\hline & \\
\hline
\end{tabular}

The components values are determined to achieve three resonance frequencies in the stop-, left-handed and righthanded bands, respectively. The dimensions of the inter digital capacitor and meandered inductors are then adjusted to achieve the same dispersion relation as that of the lumped-component counterpart

\section{SIMULATED RESULTS}

The loop antenna is designed on Rogers 5870 with substrate thickness(h) of $1.57 \mathrm{~mm}$ and a dielectric constant (cr) of 2.33. The antenna exhibits two narrow bands at 0.925 and $1.57 \mathrm{GHz}$, in addition to a wideband rang around $2.6 \mathrm{GHz}$. Thus, the antenna can cover GSM900, UMTS, Bluetooth, WiFi (2.4 GHz), WiMAX $(2.5 \mathrm{GHz})$, and GPS (1.57 GHz) bands (the unloaded loop is designed to resonate at $2.4 \mathrm{GHz}$ ). Antenna simulations are carried out on ADS . Fig. 5 shows the simulated for loaded loop antenna. Simulated radiation patterns for the loaded loop antenna are shown in Fig. 6 at the three operating bands

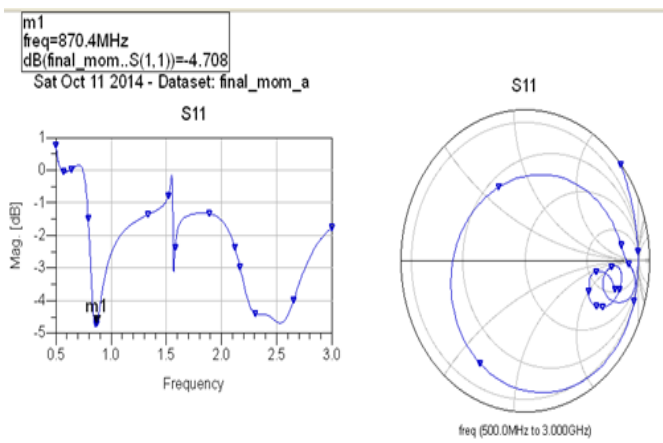


As explained in [9] and [10], the one-wavelength loop antenna has an component as shown in Fig. 4(2.4 GHz). The strong presence of indicates that the unit cell alters the current distribution along the circumference and also there is radiation due to the current flowing in it. This was not observed in the monopole loaded with the CRLH unit cell presented in [8] since the monopole preserve its donutshaped radiation patterns for all frequencies that satisfy and the unit cell was symmetrical such that it did not contribute to radiation. Also, it can be noticed that the radiation patterns are nearly symmetric although the position of the unit cell is not on the loop axis of symmetry. This indicates that the position of the added unit cell has a minor effect on the radiation pattern. Finally, it is possible to load the loop antenna with more than one CRLH unit cell similar to [8]. This is especially attractive for the loop antenna due to the large available space inside the loop, hence more radiating bands can be obtained with no size penalty. This antenna was stimulated, the implementation of a very wideband balun working from 0.9 to $2.9 \mathrm{GHz}$

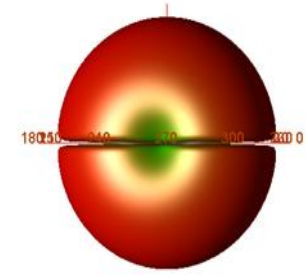

$\mathrm{f}=0.9 \mathrm{GHz}$

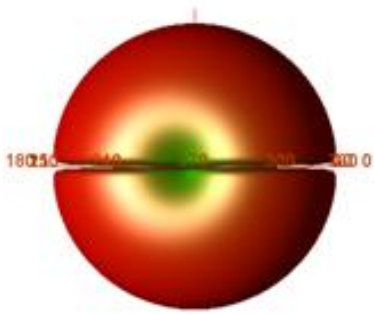

$\mathrm{f}=1.57 \mathrm{GHz}$

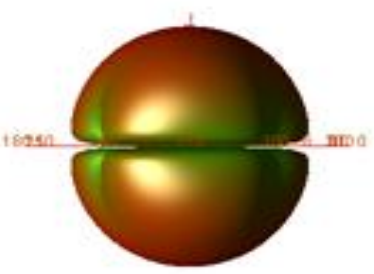

$\mathrm{f}=2.6 \mathrm{GHz}$

Fig.6.Simulated normalized radiation pattern for loop antenna

\section{CONCLUSION}

The concept of loading resonant-type antennas with CRLH unit cell was satisfied. For this case, the antenna has two narrow bands at 0.9 and $1.57 \mathrm{GHz}$ and one wide band around 2.6 GHZ. The design antenna covers the GSM900, i $(2.4 \mathrm{GHz})$, Wimax $(2.5 \mathrm{GHz})$, andGPS $(1.57 \mathrm{GHz})$ bands with quasi omnidirectional radiation pattern with verified. A Loop antenna is stimulated using ADS Software

\section{REFERENCES}

[1] RaslanA.R;Electron.Dept;Americanuniv.in.cairo,cario,Egypt;"Reso nant type of loop antennas loaded with CRLH Unit cell''Ibrahim,A.A;Safwat,A.M.E

[1] N. Engheta and R. W. Ziolkowski, Eds., Metamaterials: Physics and Engineering Explorations. New York: Wiley-IEEE Press, 2006.

[2] J. Volakis, C. C. Chen, and K. Fujimoto, Small Antennas: Miniaturization Techniques \& Applications. New York: McGraw-Hill, 2010.

[3] N. Zhu and R. Ziolkowski, "Active metamaterial-inspired broadbandwidth,efficient, electrically small antennas, " IEEE Antennas Wireless Propag. Lett., vol. 10, pp. 1582-1585, 2011.

[4] P. Jin and R. Ziolkowski, "High-directivity, electrically small, lowprofile near-field resonant parasitic antennas," IEEE Antennas Wireless Propag. Lett., vol. 11, pp. 305-309, 2012.

[5] D. Ntaikos, N. Bourgis, and T. Yioultsis, "Metamaterial-based electrically small multiband planar monopole antennas," IEEE Antennas Wireless Propag. Lett., vol. 10, pp. 963-966, 2011.

[6] M. Antoniades and G. Eleftheriades, "Multiband compact printed dipole antennas using NRI-TL metamaterial loading," IEEE Trans.Antennas Propag., vol. 60, no. 12, pp. 5613-5626, Dec. 2012.

[7] A. A. Ibrahim, A. M. E. Safwat, and H. El-Hennawy, "Triple-band microstrip-fed monopole antenna loaded with CRLH unit cell," IEEE Antennas Wireless Propag. Lett., vol. 10, pp. 1547-1550, 2011.

[8] A. A. IbrahimandA.M. E. Safwat, "Microstrip-fedmonopole antennas loaded with CRLH unit cells," IEEE Trans. Antennas Propag., vol. 60,no. 9, pp. 4027-4036, Sep. 2012.

[9] C. A. Balanis, Antenna Theory: Analysis and Design, $3^{\text {rd }}$ ed. Hoboken, NJ: Wiley, 2005.

[10] J. Volakis, Antenna Engineering Handbook, 4th ed. New York: Mc-Graw-Hill, 2007.

[11] K.-L. Wong, Planar Antennas for Wireless Communications. New York: Wiley-Interscience, 2003. 